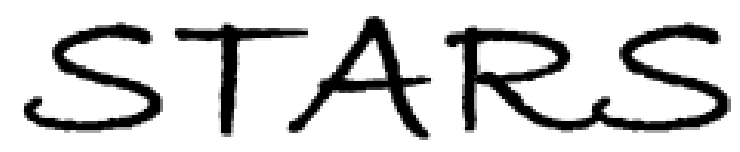

University of Central Florida

STARS

Faculty Bibliography 2000s

Faculty Bibliography

$1-1-2003$

\title{
Palladium nanoparticle arrays using template-assisted electrodeposition
}

D. Bera

University of Central Florida

S. C. Kuiry

University of Central Florida

S. Patil

University of Central Florida

University of Central Florida

Find similar works at: https://stars.library.ucf.edu/facultybib2000

University of Central Florida Libraries http://library.ucf.edu

This Article is brought to you for free and open access by the Faculty Bibliography at STARS. It has been accepted for inclusion in Faculty Bibliography 2000 s by an authorized administrator of STARS. For more information, please contactSTARS@ucf.edu.

\section{Recommended Citation}

Bera, D.; Kuiry, S. C.; Patil, S.; and University of Central Florida, "Palladium nanoparticle arrays using template-assisted electrodeposition" (2003). Faculty Bibliography 2000s. 3624.

https://stars.library.ucf.edu/facultybib2000/3624

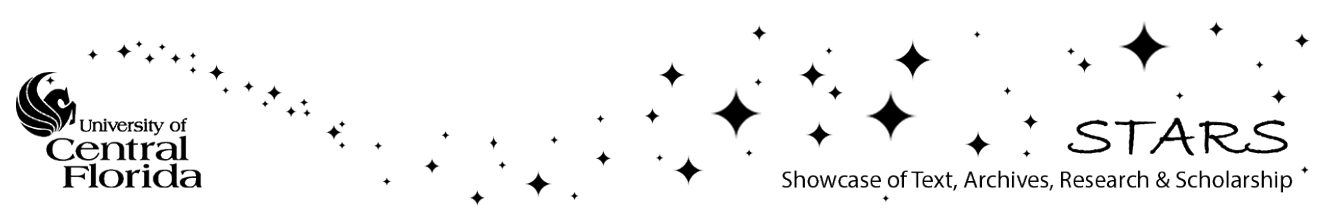




\section{Palladium nanoparticle arrays using template-assisted electrodeposition}

Cite as: Appl. Phys. Lett. 82, 3089 (2003); https://doi.org/10.1063/1.1572465

Submitted: 14 November 2002 . Accepted: 12 March 2003. Published Online: 29 April 2003

D. Bera, S. C. Kuiry, S. Patil, and S. Seal

\section{ARTICLES YOU MAY BE INTERESTED IN}

Electrodeposition of Pd nanoparticles on single-walled carbon nanotubes for flexible hydrogen sensors

Applied Physics Letters 90, 213107 (2007); https://doi.org/10.1063/1.2742596

A comprehensive review of $\mathrm{ZnO}$ materials and devices

Journal of Applied Physics 98, 041301 (2005); https://doi.org/10.1063/1.1992666

\section{Applied Physics Letters}

Mid-IR and THz frequency combs special collection

\section{Read Now!}




\title{
Palladium nanoparticle arrays using template-assisted electrodeposition
}

\author{
D. Bera, S. C. Kuiry, S. Patil, and S. Seal ${ }^{\mathrm{a})}$ \\ Advanced Materials Processing Center (AMPAC), and Mechanical, Materials and Aerospace Engineering \\ (MMAE), Surface Engineering and Nanotechnology Facility, Eng. 1, No. 381, University of Central \\ Florida, 4000 Central Florida Boulevard, Orlando, Florida 32816
}

(Received 14 November 2002; accepted 12 March 2003)

\begin{abstract}
Palladium nanoparticles are being increasingly considered as room-temperature hydrogen sensors and storage materials. Pd nanoparticle arrays have been synthesized using template-assisted electrodeposition. The template based on $\mathrm{Al}$ film on a polymeric substrate was characterized by scanning electron microscopy and energy dispersive spectroscopy. X-ray photoelectron spectroscopy study confirmed that the deposited nanoparticles were of metallic Pd. High-resolution transmission electron microscopy investigation revealed that Pd nanoparticles consisted of a large number of nanocrystallites in the size range of 5-10 nm. (C) 2003 American Institute of Physics. [DOI: $10.1063 / 1.1572465$ ]
\end{abstract}

Metal nanomaterials in various forms such as wire, rod, tube, and spherical shapes are of great interest ${ }^{1-3}$ as components of technologically important microsystems for gas sensing and other systems pertaining to hydrogen storage, magnetic storage media, electrical and optical applications. ${ }^{4-7}$ Template and step-edge methods ${ }^{8}$ are used for the preparation of metallic nanowires and nanorods of Pt, $\mathrm{Au}$, and Mo. Synthesis of mesoscopic wires of palladium through the step-edge method has also been reported ${ }^{4}$ using a graphite surface as an electrode. Pd nanoparticles and nanorods in the form of periodic arrays are of great importance because of their potential applications for sensing ${ }^{4}$ and storage of hydrogen at room temperature. However, an easy and versatile method for the synthesis of uniformly spaced arrays of Pd nanoparticles and nanorods with a narrow size distribution is yet to be reported for aforesaid applications. The present study is an attempt to develop a method to synthesize arrays of Pd nanoparticles combining template and electrodeposition processes.

Palladium nanoparticles were deposited on the surface of a template through potentiostatic electrodeposition at $0.3 \mathrm{~V}$ for $400 \mathrm{~s}$ from a $2 \mathrm{mM}$ palladium nitrate solution using EG\&G Potentiostatic Instruments (Model 263A). The current density was optimized in the range of $8-20 \mu \mathrm{A} \mathrm{cm}^{-2}$ under such electrochemical conditions. The template used in the present investigation was an aluminum thin film on top of a polycarbonate substrate derived from a compact disk. Regular arrays of circular- and oblong-shaped holes were formed on the top surface of the aluminum thin film with the help of a compact disk drive with data recording capability using a laser. The surface morphology and the cross section of the blank template have been characterized using scanning electron microscopy (SEM) (Model: JEOL T-300) and focussed ion beam (FIB) equipment [Model: FEI FIB 200 transmission electron microscope (TEM)], respectively. Figure 1(a) presents SEM micrograph of such periodic holes or pits on the aluminum substrate. An FIB image of the cross sections of two pits are shown in the inset of Fig. 1(a) along

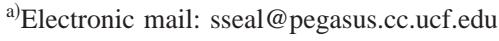

with the cross section of the Pt layer which was deposited on the template-surface prior to FIB milling to protect it from the ion beam. Energy dispersive spectroscopy (EDS) spectrum of the top surface of template prior to Pd deposition, as shown in Fig. 1(b), confirms the presence of aluminum, carbon, and oxygen. Carbon and oxygen peaks in the EDS spec-
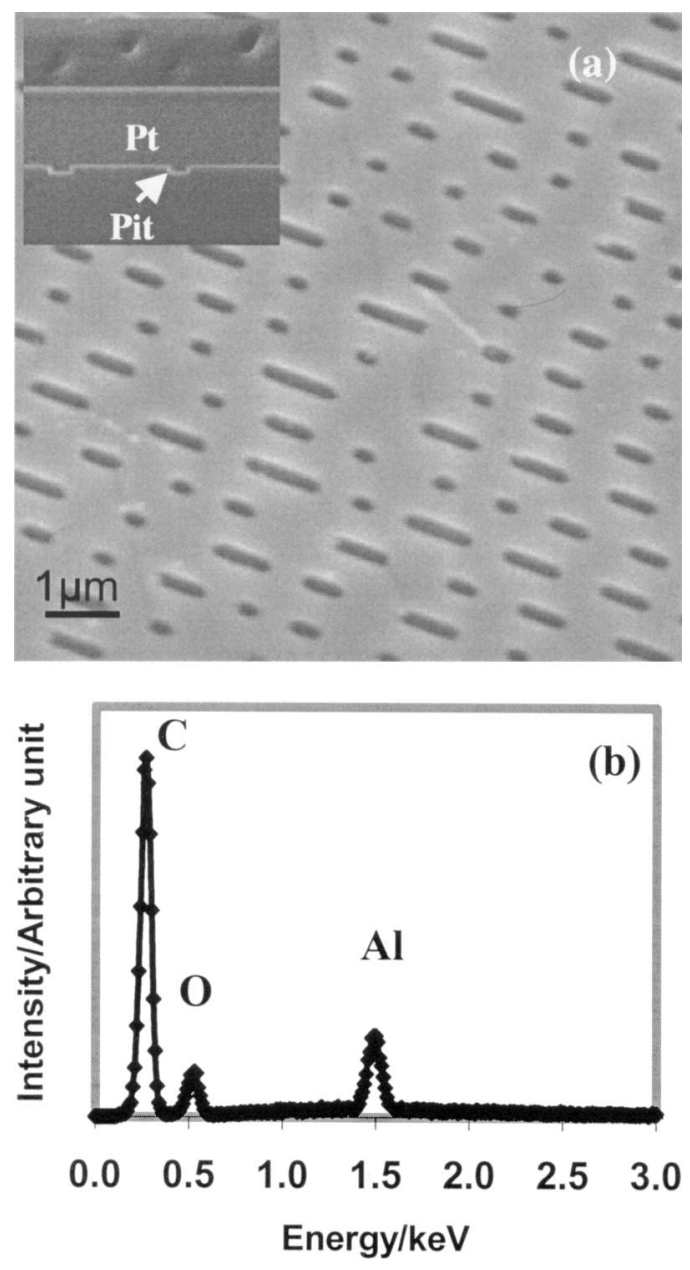

FIG. 1. (a) SEM micrograph of the top surface and FIB cross section showing the depth of the holes (inset) of template prior to Pd deposition, and (b) corresponding EDS spectrum. 

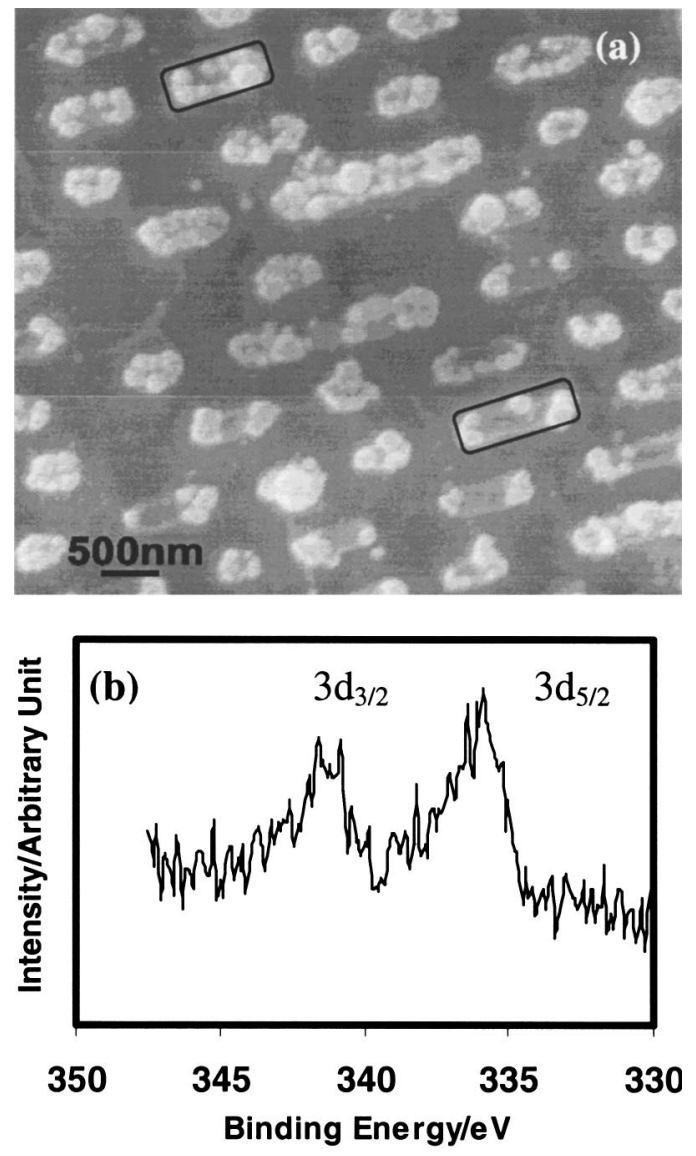

FIG. 2. (a) SEM micrograph of the array of Pd-nanoparticles clusters after electrodeposition on the templates, and (b) $\operatorname{Pd}(3 d)$ XPS envelope.

trum have come from the polycarbonate film which was present underneath the aluminum thin film. Figure 2(a) shows the SEM micrograph of the template after the electrodeposition of Pd nanoparticles. Figure 2(b) shows the X-ray photoelectron spectroscopy (XPS) spectrum of $\operatorname{Pd}(3 d)$ envelope confirming the metallic Pd particles. XPS spectrum was collected using PHI 5400 ESCA system. XPS Pd( $\left.3 d_{5 / 2}\right)$ and $\operatorname{Pd}\left(3 d_{3 / 2}\right)$ peaks were observed at binding energy values of 335.9 and $341.2 \mathrm{eV}$, respectively. Such binding energy values are similar to that reported for Pd metals in literature.

Figure 2(a) suggests that the stable Pd nuclei were preferably nucleated at the holes of the templates. Subsequent to exposure to the electrochemical system, the growth of such nuclei took place eventually filling the pits. Further passage of electrical current resulted in an overgrowth of particles. Hence, the present study indicates that the size of these template-assisted electrodeposited Pd particles can be controlled by controlling the time and electrical current density in the electrodeposition process. Pd arrays have been prepared using the aforementioned template for their preferential growth at the holes. Although the exact reason of such preferential nucleation is not clear at this time, however, the influence of topography may not be ruled out. The effect of curvature on altering the electrical charge density at the pits may have possibly created a situation for easy nucleation at these locations. The SEM micrograph in Fig. 2(a) revealed that the Pd particles were oriented as per the orientation of the holes in the template. Such preferentially deposited Pd nanoparticles could eventually be grown longitudinally to
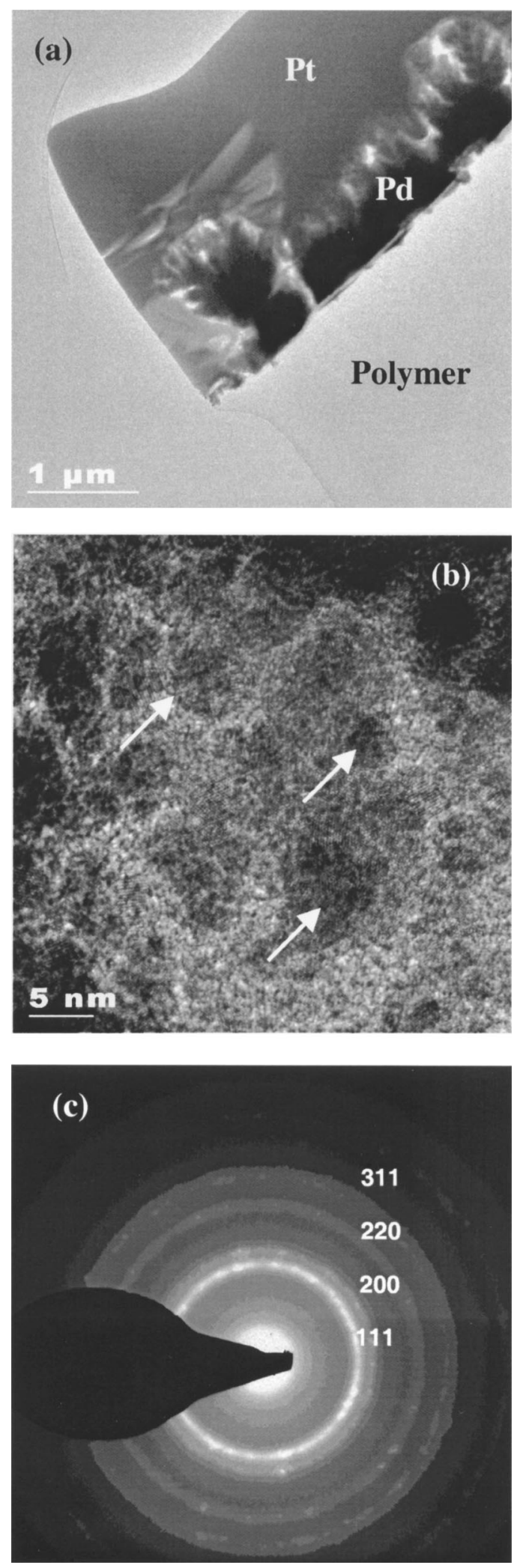

FIG. 3. (a) FIB lift-out on a $\mathrm{Cu}$ grid showing cross section of agglomerated Pd particles, (b) HRTEM image showing Pd nanocrystallites, and (c) SAED pattern.

form nanowires under controlled conditions, which can be used for hydrogen sensing applications.

Further examination reveals that these nanoparticles as shown in Fig. 2(a) consisted of a number of smaller nanoparticles. High-resolution TEM (HRTEM) study was carried out to investigate the size and structure of the individual 
nanocrystallite. A protective platinum coating was given on Pd particles grown on the templates using the FIB and milled to have a $200 \mathrm{~nm}$ thick Pd agglomerates lift-out specimen as shown in Fig. 3(a). The lift-out specimen was subsequently used for HRTEM (Model: Philips 300 TECNAI) study at 300 $\mathrm{kV}$. The HRTEM image of one such agglomerated particle is shown in Fig. 3(b), which reveals the presence of a number of nanocrystallites of $\mathrm{Pd}$ in the size range of 5-10 nm. The selected area electron diffraction (SAED) pattern of the Pd crystallites is presented in Fig. 3(c), which confirms the facecentered-cubic lattice structure of these nanocrystallites.

The array of Pd nanoparticles with controlled size and shape was synthesized using an easy procedure that combines the template and the electrodeposition methods. Such nanoparticles consist of a number of nanocrystallite $\mathrm{Pd}$, which are ideal starting materials for hydrogen sensing and storage devices. These nanoparticle arrays can be grown in the templates under a controlled manner leaving a nanospacing between two adjacent particulates for the sensing of hydrogen gas at room temperature with high sensitivity.
The authors would like to thank the NSF for Grant Nos. EEC 0136710 and 0085639, FSEC-NASA Glenn, Florida Space Grant Consortium, and MCF facilities at AMPAC, $\mathrm{UCF}$, Orlando for financial and equipment supports.

${ }^{1}$ G. Fasol, Science 280, 5363 (1998).

${ }^{2}$ S. Hoeppener, R. Maoz, S. R. Cohen, L. Chi, H. Fuchs, and J. Sagiv, Adv. Mater. 14, 1036 (2002).

${ }^{3}$ T. Hassenkam, K. Norgaard, L. Iversen, C. J. Kiely, and M. Brust, Adv. Mater. 14, 1126 (2002).

${ }^{4}$ F. Favier, E. C. Walter, M. P. Zach, T. Benter, and R. M. Penner, Science 293, 2227 (2001).

${ }^{5}$ C. M. Lieber, Solid State Commun. 107, 607 (1998).

${ }^{6}$ G. Fasol and K. Runga, Appl. Phys. Lett. 70, 2467 (1997).

${ }^{7}$ C. A. Foss, in Nanoparticles: Synthesis, Characterization and Application, edited by D. L. Feldhiem and C. A. Foss (Marcel Dekker, New York, 2002).

${ }^{8}$ M. P. Zach, K. H. Ng, and R. M. Penner, Science 290, 2120 (2000).

${ }^{9}$ J. F. Moulder, W. F. Stickle, P. E. Sobol, and K. D. Bomben, in Handbook of X-ray Photoelectron Spectroscopy, edited by J. Chastain (Physical Electronics Division, Perkin-Elmer Corporation, Eden Prairie, Minnesota, 1984). 